\begin{tabular}{|c|c|c|}
\hline J & $\begin{array}{l}\text { International Journal of Current Research in } \\
\text { Biosciences and Plant Biology }\end{array}$ & $\equiv$ \\
\hline & Volume 6 • Number 12 (December-2019) • ISSN: 2349-8080 (Online) & \\
\hline $\begin{array}{l}\text { EXCELLENT } \\
\text { PUBLISHERS }\end{array}$ & Journal homepage: www.ijcrbp.com & \\
\hline
\end{tabular}

\title{
Isolation and enumeration of fungi and determination of contributing factors to fungal spoilage in maize (Zea mays L.) originated from east and west Shewa Zones of Oromia, Ethiopia
}

\author{
Temesgen A. Gelaw ${ }^{1}$ and Teshome G. Biru ${ }^{2 *}$ \\ ${ }^{1}$ Department of Biotechnology, College of Natural and Computational Science, Debre Birhan University, \\ P.O. Box 445, Debre Birhan, Ethiopia \\ ²Department of Applied Biology, College of Applied Natural Science, Adama Science and Technology University, \\ P.O. Box 1888, Adama, Ethiopia \\ *Corresponding author; e-mail: teshome.geremew@gmail.com
}

\begin{tabular}{|c|c|}
\hline le Info & \multirow{4}{*}{$\begin{array}{l}\text { Fungal spoilage in maize resulted in grain deterioration and mycotoxin contamination. } \\
\text { In Ethiopia, maize production is prone to losses due to mold contamination. The } \\
\text { purpose of this study was to isolate fungi and determine the contributing factors to } \\
\text { fungal spoilage in Maize. } 72 \text { maize samples were collected based on incremental } \\
\text { sampling method. Fungal isolation was done on Potato Dextrose Agar amended with } \\
\text { o.o1\% chloramphenicol. Fungal colonies were purified by sub-cultured on PDA. } \\
\text { Morphological and microscopic characterization of the isolates was done based on } \\
\text { fungal identification manual. From } 1080 \text { maize grains, } 613 \text { fungal isolates were } \\
\text { recorded with } 54.1 \% \text { mean value where the majorities were belongs to the genus } \\
\text { Fusarium. Grains collected from warehouse were more infected ( } 58.88 \% \text { ) followed by } \\
\text { store, open market and household. Overall, the prevalence of fungal infection in the } \\
\text { study sites was high. Awareness creation, cumulative integrated management, } \\
\text { monitoring, and precautionary measures are recommended. }\end{array}$} \\
\hline $\begin{array}{l}\text { Date of Acceptance: } \\
\text { 30 November } 2019\end{array}$ & \\
\hline Keywords & \\
\hline $\begin{array}{l}\text { Food contamination } \\
\text { Fungal spoilage }\end{array}$ & \\
\hline
\end{tabular}

\section{Introduction}

Cereals represent a substrate that facilitates mold growth and contamination. Maize (Zea mays L.) is the most commonly contaminated cereal followed by wheat, sorghum, oat, barley and rice (Jelka et al., 2017). Maize is an agricultural crop of worldwide importance grown both for the food industry and for other purposes (Jan et al., 2012). Fungal contamination becomes an issue of special concern during rainy seasons characterized by substantial temperature variations which favor mold contamination and mycotoxin production
(Pleadin et al., 2013). In substantial proportions of maize-producing areas worldwide, the crops are subjected to contamination from mycotoxins (Tomoko et al., 2007; Jelka et al., 2017).

In most parts of Africa, the mycotoxin hazard is very high because the limited food supply has forced people not to reject any material that can be used as food, even if the organoleptic quality of the food has been changed by molds. The prevailing malnutrition and poverty jeopardize people's susceptibility to very low levels of mycotoxins. This situation is further aggravated 
by the warm humid tropical conditions and improper drying and storage practices (Dejene et al., 2004) which provide optimal conditions for mold growth and subsequent build-up of mycotoxins within a short spell of time (Samuel et al., 2011).

In Ethiopia, maize is being grown in different parts of the country (Yibrah and Dereje, 2015). Fungal spoilage is the most retarding factor for maize yield loss in terms of quality and quantity where the occurrence of maize fungal contamination in developing countries gets global attention (Maria et al., 2013). Fungal spoilage jeopardizes both human and animal health (Pleadin et al., 2013). Members of the fungal genera Aspergillus, Fusarium, and Penicillium cause frequent and problematic contamination of foods and feeds (Jolly et al., 2011, Temesgen and Teshome, 2018). These are found in many feeds and foodstuffs especially in plants during pre and post-harvest, transportation, processing and storage and are detected in cereal crops (Ezekiel et al., 2014).

More than 9 million smallholder households grow maize in Ethiopia at present (Tsedeke et al., 2015) where maize production is higher and is the second highest in Sub-Saharan Africa. According to World data atlas, maize production of Ethiopia increased from 2.34 million tons in 1998 to 8.12 million tons in 2017 growing at an average annual rate of $7.57 \%$ (Hadush et al., 2017). In terms of internal distribution of maize production, Oromia (61\%), Amhara (20\%) and Southern Nations Nationalities and Peoples Region (12\%) are the dominant areas of maize cultivation (CSA, 2013). Accordingly, 80\% of the maize produced by smallholders is used for household consumption without being processed, $10 \%$ for sale and the remaining $10 \%$ for seed and other purposes (Rashid et al., 2013). The majority of farmers (more than 93.3\%) use traditional maize storage containers that expose their stored grains to attack by storage pests, molds and or other factors. The average actual loss per household is about $12 \%$ of the average total grain production (Dubale, 2018).

In Ethiopia the major contributing factors for high postharvest losses relates with poor postharvest infrastructure and marketing systems, poor research and improvement capability, and insufficiencies in guidelines and information sharing (Dubale, 2018). However there are limited researches on the prevalence of fungi on maize and its prevention approaches in Ethiopia. Therefore, this study aims to magnify fungal prevalence and determine the contributing factors for fungal spoilage on maize.

\section{Materials and methods}

\section{Description of sampling area}

Maize samples were collected from four major maize producing districts of East and West Shewa zone of Oromia, Ethiopia (Fig. 1). Bako Tibe and Dano districts from Western Shewa; Adami Tullu and Arsi Negelle districts from Eastern Shewa zone were used in the study. From each district two kebeles and a town were selected for sample collection. The kebeles were Seyu Gambella, Sayoo and Dano Shenen from Dano district; Odda Anshura, Anneno Shisho and Adamu Tulu town from Adami Tulu district; Bako town, Dambi Dimma and Dambi Gobbu from Bako Tibe district and Arsi Negelle town, Hadah Bioo and Rafuu Hargisa from Arsi Negelle districts. All the study areas were selected based on maize production potential.

\section{Sample type, size and sampling technique}

The experimental materials used in this study were maize grains collected from twelve different areas. Sample sites were purposefully selected based on maize production potential according to Central Statistical Agency of the country and Oromia regional and zonal agricultural office.

A total of 72 maize samples of $1 \mathrm{~kg}$ were collected from household, warehouse, open market and store based on incremental sampling method. Each selected districts were represented by two rural kebeles and one town sampling. During sampling process; sample history including, source of collection, storage duration after harvest, means of harvest, moisture content during collection, storage condition (type of storage) and the use of fertilizer and/or compost were recorded.The grain moisture content was measured using an electronic moisture tester (HOH-Express-HE-50, Germany) immediately after collection. Maize samples were packed in polyethylene bag, labeled and stored at $4^{\circ} \mathrm{C}$ until further analysis. 


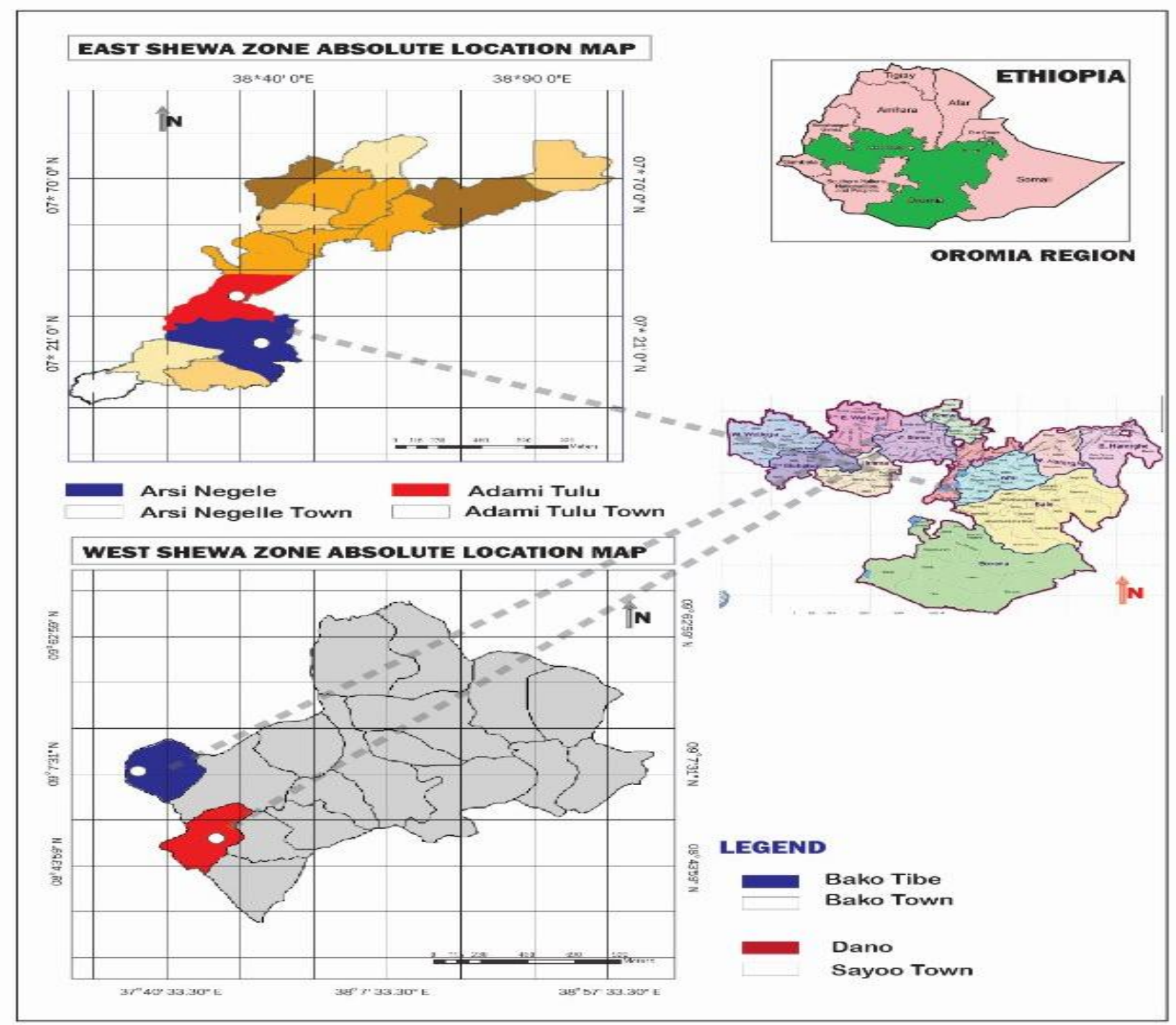

Fig. 1: Map of Ethiopia depicting the stud areas in Oromia regional state.

\section{Fungal isolation and morphological characterization}

From each sample, 15 maize grains were randomly selected and surface sterilized by treating with 70 $\%$ ethanol for 2 minutes. Maize grains were rinsed three times with sterile distilled water. Potato Dextrose agar (PDA) (Hi-Media Laboratories Ltd. Mumbai, India) medium amended with $0.01 \%$ chloramphenicol was used for plating experiments. Five surface sterilized grains were aseptically placed on a Petri dish containing PDA in triplicate and incubated upright at $25^{\circ} \mathrm{C}$ for 5-7 days. Fungal colonies were picked up with a sterile needle and purified by transferring to PDA medium. The pure isolates were then transferred and preserved on PDA slant at $4^{\circ} \mathrm{C}$.

Fungal isolates were grouped to genus level based on fungal identification manual (Barnett and Hunter, 1998; Sarah et al., 2016). Isolates were observed based on colony growth rates, texture, degree of sporulation, color of mycelia, shape of conidial heads, vesicles, the number of branching points between vesicle and phialides. Iodine glycerol solution (0.5\%) and lacto phenol cotton blue dye were used to perform slide culture technique (Patrick et al., 2010). The frequency of fungal infection and total microbial load were calculated according to AOAC (1995). 


\section{Data analysis}

For statistical evaluation of the data, SPSS software version 20 was used to generate descriptive statistics. Pearson correlation was used to assess the relationship between fungal infection and moisture content of the samples. To determine the influence of the environmental predictive factors on the response factors Kruskal-Wallis test $(\alpha=$ 0.05) was performed.

\section{Results and discussion}

\section{Fungal isolation from maize}

Mycological analysis of the maize samples showed that the overall fungal incidence was $54.1 \%$ (Table 1). The result showed the genus Fusarium was the predominant $(73.08 \%)$ followed by Penicillium (8.48\%), Muchor and Rhizopus (7.5\%), Aspergillus (5.38\%) and others unidentified (5.54\%) (Fig. 2A). Dano district showed higher mean percent of fungal infection (68.15\%) followed by Adami Tullu (60.37 \%), Bako Tibe (50\%) and Arsi Negelle (37.78\%) (Fig. 2B). West Shewa zone showed higher percent of fungal incidence (59.07\%) and also East Shewa zone showed considerable fungal prevalence (49.07\%). The result of this study was lower than the finding of Amare (2010) who analysed fungal incedince on maize samples collected from Adama, Ambo and Dire Dawa and reported 94\% Aspergillus, 76.5\% Fusarium and 64\% Penicillium fungal prevalence. However, the result of fungal prevalence obtained in this study is higher than recent findings of Negasa et al., (2019) in Bako, Western Shewa, 39.4\% Fusarium and 26.7\% Aspergillus from maize.

Fusarium species associated with maize grain were identified in Ethiopia (Tesfaye and Dawit, 1998). Factors such as moisture content of the product (Gtorni et al., 2009), temperature, storage time and degree of fungal contamination prior to storage, insect and mite activity facilitate fungi dissemination (Suleiman and Omafe, 2013). During storage, several kinds of fungi can remain associated to maize grains either causing deterioration or simply remain viable to infect germinating seedling (Castellari et al., 2010). Tesfaye and Dawit (2000) founded three species of Fusarium (F. moniliforme, F. subglutinans, and $F$. graminearum) to be highly associated with maize samples around Shashemene and Alemaya. A study by Yesuf et al., (2015) also reported more than $50 \%$ of Fusarium contamination in Sorghum, maize, common bean, coffee, mung bean and cowpea in South Omo and Segen Peoples Zone of Ethiopia.

This study best fits with Chemeda et al. (2018), a research conducted in southwestern Ethiopia and the genus Fusarium, Penicillium and Aspergillus were found highly dominant. There is higher Fusarium contamination in different parts of the country. This is due to the boundary less distribution of the fungus and survival in different agro ecological locations. Additionally, since Fusarium can cause systemic infection to maize it can lead to kernel infection and showed higher prevalence. Moreover, the other storage fungi recorded were attempted due to poor drying before harvest.

\section{Correlation of environmental factors with fungal prevalence}

Correlation analysis of moisture content, storage duration and fungal percent of infection showed that moisture content and storage duration were negatively correlated with fungal prevalence and found to be statistically insignificant $(p>0.05)$. Environmental conditions and climatic factors are the most important to the contamination of maize grains before and after harvest. The grain moisture content and temperature potentially affects the growth of mycotoxigenic fungi and spread of infection to the maize grain before and after harvest (Kana et al., 2013). But according to this study the factor are negatively correlated with fungal spoilage and even if there is weak correlation among them, there is considerable fungal incidence recorded. Since the samples were collected after harvest; during storage when there is moisture to the grain, the fungi gets favorable opportunity for growth and specifically plays a role for Fusarium contamination.

Maize storage type analysis result revealed that storage using plastic bag showed higher fungal percent of infection (69.78\%) followed by gotera (51.11\%) and fertilizer bag (49.63\%) (Fig. 3). Plastic bags are occasionally used for storage in Ethiopia. The higher percentage of fungal infection observed on maize stored in plastic bag may be due to lack of ventilation and 
accumulation of water vapor in the plastic bag which leads to germination of mold on stored maize (Dubale, 2014).Therefore, the reason behind the higher incidence of fungal infection in the plastic bags was due to the lesser air ventilation. Gotera storage system is also widely utilized in Ethiopia. In this study $51.1 \%$ of fungal infection of maize grains was recorded which shows higher prevalence and this was due to poor drying of the grains before harvest.

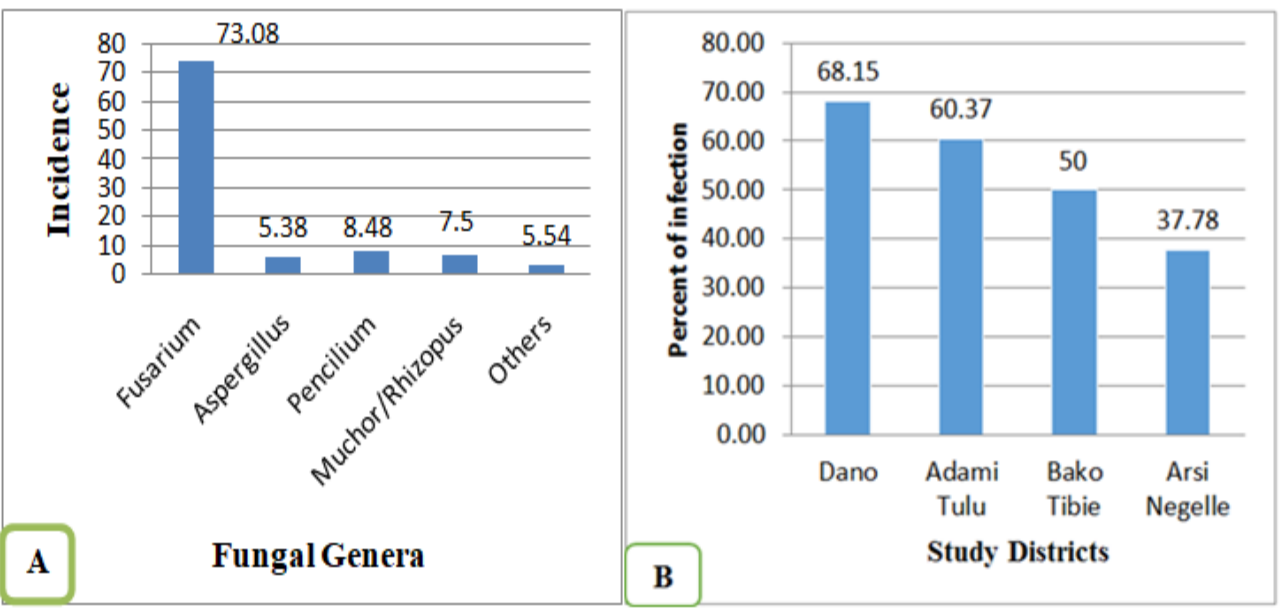

Fig. 2: Incidence of fungal genera (A) and percent of fungal infection on maize in four districts (B).

Table 1. Mean fungal percent of infection on maize sampels obtained from 12 kebeles

\begin{tabular}{lllll}
\hline S.No. & Kebele & Mean infection & N & Standard error \\
\hline 1 & Adami Tullu Town & 48.8 & 6 & \pm 3.24 \\
2 & Anneno Shisho & 60.0 & 6 & \pm 4.66 \\
3 & Arsi Negelle Town & 46.6 & 6 & \pm 1.40 \\
4 & Bako Town & 55.5 & 6 & \pm 2.56 \\
5 & Dambi Dima & 31.1 & 6 & \pm 1.46 \\
6 & Dambi Gobu & 63.3 & 6 & \pm 2.75 \\
7 & Dano Shenen & 63.3 & 6 & \pm 3.24 \\
8 & Hadah Bioo & 33.3 & 6 & \pm 1.31 \\
9 & Odda Anshura & 72.2 & 6 & \pm 3.73 \\
10 & Rafuu Hargisa & 33.3 & 6 & \pm 1.72 \\
11 & Sayoo & 73.3 & 6 & \pm 3.61 \\
12 & Seyu Gambela & 67.7 & 6 & \pm 2.45 \\
& Total & $\mathbf{5 4 . 1}$ & $\mathbf{7 2}$ & $\mathbf{+ 3 . 1 5}$ \\
\hline
\end{tabular}

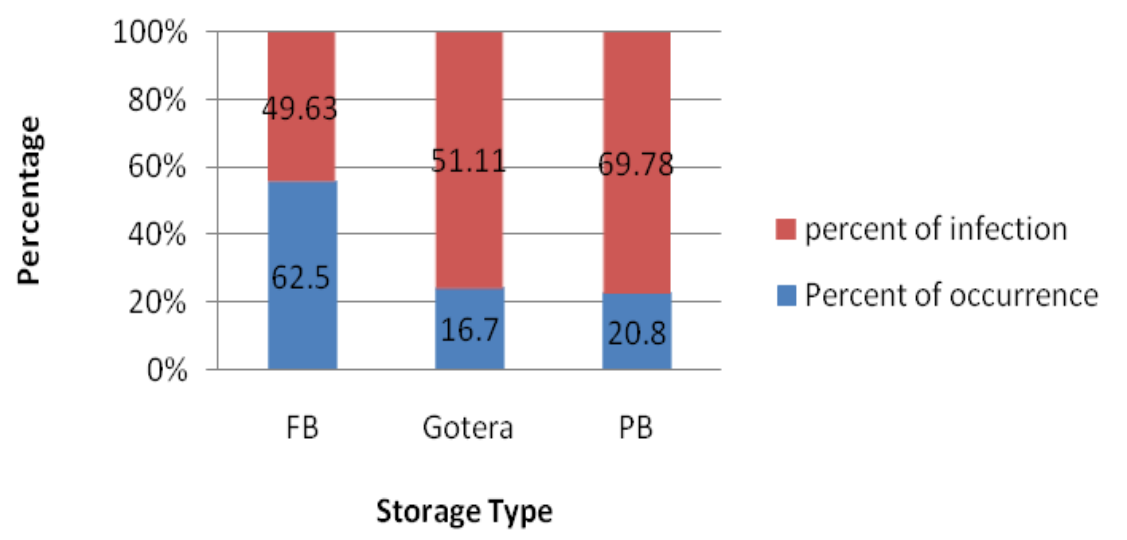

Fig. 3: Maize storage type versus percent of infection ( $\mathrm{FB}=$ Fertilizer bag, $\mathrm{PB}=$ Plastic bag).

The percent of occurrence indicates the percentage of the storage types used by the society in the study area. 
The maize samples were obtained from four different sources (household, warehouse, open market and store). The grains collected from warehouse were more infected $(58.88 \%)$ followed by store (55\%), open market $(54.28 \%)$ and household (52.78\%) (Fig. 4).
This indicates that there were lesser aeration with higher level of fungal infection in the warehouse and store. Moreover in the open market the grains have higher probability of contact with dust, soil and dung which also favors fungal growth.

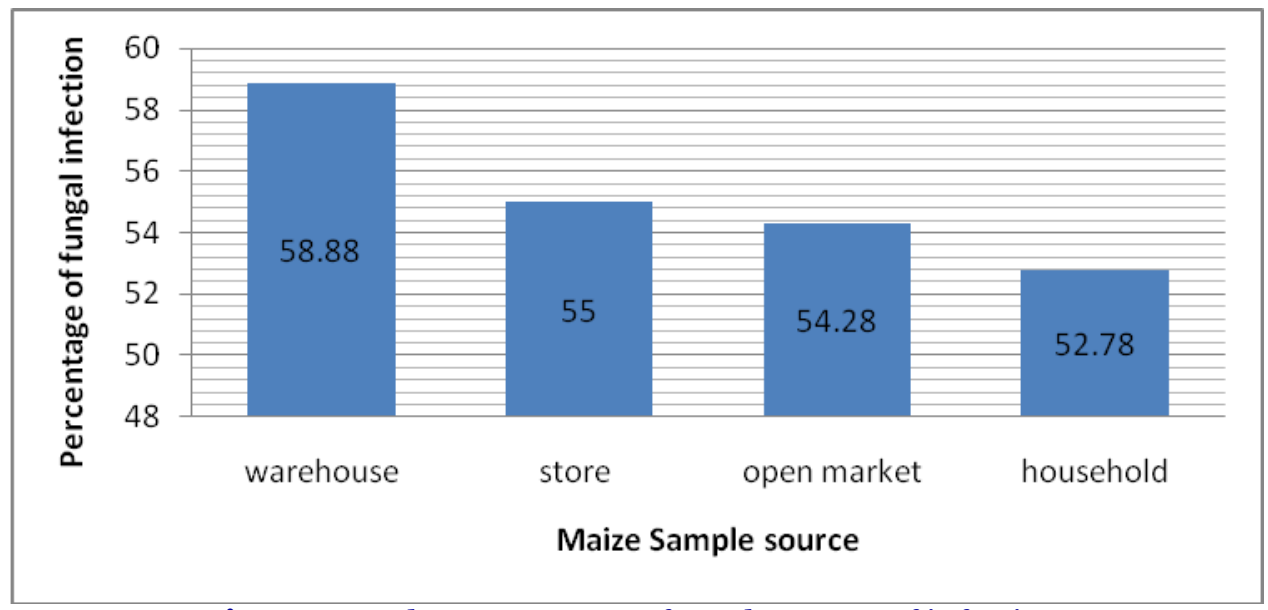

Fig. 4: Sample source versus fungal percent of infection.

Maize samples moisture content obtained in this study ranges from 11 to $17 \%$. Fungal infection ranges from 13.3 to $100 \%$. The mean moisture content was $14.16 \%$ and mean percent of fungal infection (54.1\%). The minimum moisture content with $80 \%$ fungal infection was obtained from west shewa zone, Dano district of Dano shenen Kebele on manually harvested and gotera stored maize. In other way, the higher moisture content value was recorded from east shewa zone of Arsi Negele district in the town from manually harvested maize stored on fertilizer bag for two month. Moreover, Adami tulu town and Arsi Negele town represented the minimum and maximum mean moisture content value. Based on the ANOVA analysis, the relationship between moisture content and fungal percent of infection is statistically insignificant $(\mathrm{p}>0.94)$.

The main factors which greatly affect grain storability include grain moisture content, storage temperature, insects infestation and molds invasion which are highly interrelated. If grain moisture content is too high monitoring other conditions will not prevent the grain from fungal spoilage. The grain should be placed in the storage at less than $14 \%$ moisture wet basis and preferably
$13 \%$ for greater safety (Dubale, 2014). Pockets of high moisture grain or inclusion of green leaf material with the grain can affect quality of all the grain in storage because of moisture movement (Dubale, 2014).

According to National Agricultural Commodities Marketing Association Standards (Queensland, Australia), the maximum moisture limits for trading and storage of maize grains is 14\% (Dubale, 2014). Aeration will slow the rate of deterioration of high moisture grain, but if the moisture is more than two or three percent above the limits, it should be dried before long term storage (Laura, 2019). Early harvesting of grain at higher moisture produces higher quality and higher yield of grain, but those advantages are lost unless aeration and drying are used to minimize losses in storage (Dubale, 2014).

In this study, the mean moisture content (14.16\%) was found above the standard limit of National Agricultural Commodities Marketing Association Standards and associated with higher fungal contamination. However, the association of mean moisture content with mean percentage of fungal infections is statistically insignificant $(p=0.09)$. As 
the moisture content increases above the standard levels, storage fungi invasion increases (Laura, 2019). The reason for the moisture content above the safe limit was due to initial exposure of sampled grains to different ambient temperature and relative humidity. The statistical insignificance may be due to the variation of fungal contamination in samples.

From the current finding, there was no significant difference between the use of fertilizer and compost during maize production in relation to fungal infection, although $54.1 \%$ of fungal infections were recorded from maize produced using fertilizer use and $55.65 \%$ from maize produced using compost. Nutrients are the determinant factors for growth and productivity, particularly under adverse conditions (El Kinany et al., 2018). According to Tsedeke et al. (2015), Ethiopian farmers have historically used organic fertilizers (such as farmyard manure, compost, crop residue, and household refuse) for agricultural production and today commercial fertilizer use is the dominant input that goes with modern varieties where all of Ethiopia's mineral fertilizer is imported. Organic fertilizers have higher favorable condition for fungal growth because compost addition enhanced hyphal growth and sporulation (Wei et al., 2018).

The storage duration versus fungal percent of infection analysis revealed that grains stored for one month showed $63.7 \%$ (Fig. 5). Thus, storage duration and percent of fungal infection have weak negative correlation with statistical insignificance $(\mathrm{p}=0.23)$. This implies as the storage time increases the incidence of fungal contamination decreases. At normal condition, as the storage period increases, the incidence and frequency of all fungal species will also increase which may be due to increase of relative humidity in the storage that favors the rewetting of the stored maize grains (Negasa et al., 2019). In contrary, this study found that as the storage time increases the mean percent fungal contamination decreases. This was due to the higher moisture at harvest season and longer storage of the grain in the fertilizer bag provides aeration thereby reduce fungal contamination. More over this variation may be due to the grains varied fungal exposure.

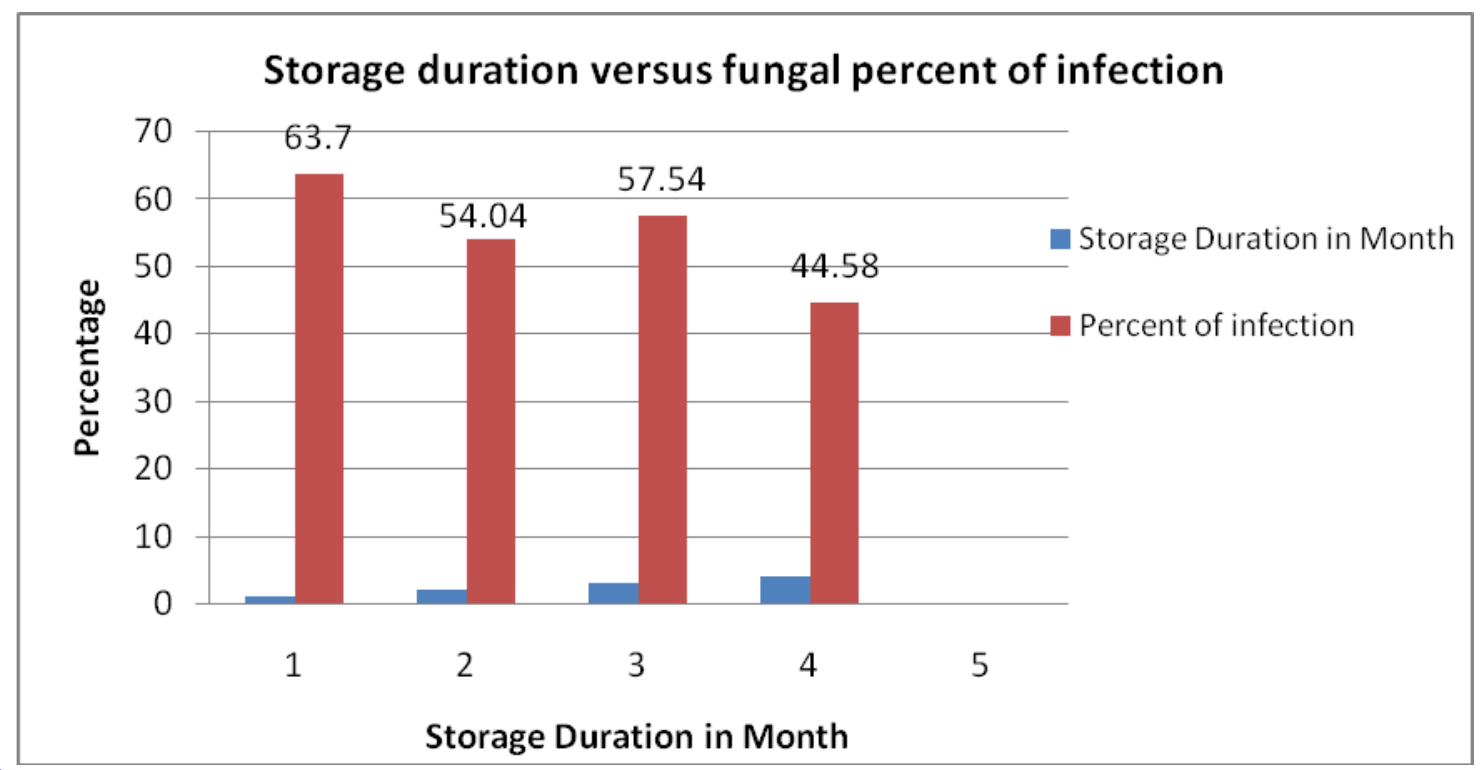

Fig. 5: Mean comparison of percentage of storage duration in month with fungal percent of infection $($ STD for storage duration $=1.08$ and percent of infection $=26.79),(p=0.29)$.

\section{Fungal characterization}

From the total of 1080 maize grains analyzed about $613(56.8 \%)$ were found contaminated with different fungi. Every fungal colony that appeared on the grains were counted as the genus Aspergillus, Penicillium, Mucor, Rhizopus, Fusarium and others based on morphological and microscopic 
observation. From the 613 isolated fungi $73.1 \%$ were Fusarium followed by $8.5 \%$ Penicillium, $7.5 \%$ Mucor/Rhizopus, 5.4\% Aspergillus and 5.5\% others unidentified fungi (Table 2). Odda Anshura Kebele from Adami Tullu district and Arsi Negelle Town from Arsi Negelle District showed the higher and lower mean percentage of Fusarium infection respectively. In contrary, Odda Anshura and Bako town showed no fungal infection for Aspergillus and Penicillium respectively.

Table 2. Fungal genera isolated from maize samples collected from different kebeles.

\begin{tabular}{llllll}
\hline \multirow{2}{*}{ Kebele } & \multicolumn{2}{l}{ Fungal incidence (\%) } & & & \\
\cline { 2 - 6 } & Fusarium & Penicillium & Aspergillus & Mucor/Rhizopus & Others \\
\hline Seyu Gambela & 80.79 & 5.55 & 4.88 & 2.38 & 6.38 \\
Sayoo & 62.2 & 3.66 & 2.56 & 2.08 & 29.48 \\
Dano Shenen & 69.84 & 3.33 & 9.72 & 2.38 & 0 \\
Odda Anshura & 94.16 & 12.96 & 0 & 4.81 & 0 \\
Anneno Shisho & 65.04 & 2.39 & 6.66 & 27 & 0 \\
Adami Tulu town & 65.21 & 27.73 & 8.05 & 7.79 & 2.08 \\
Bako Town & 78.67 & 0 & 3.03 & 14.69 & 3.59 \\
Dambi Dima & 78.19 & 14.3 & 5.41 & 2.08 & 0 \\
Dambi Gobu & 84.18 & 5.12 & 4.06 & 4.06 & 2.56 \\
Arsi Negelle Town & 58.82 & 16.27 & 7.22 & 15.59 & 2.08 \\
Hadah Bioo & 74 & 5.55 & 20.43 & 0 & 0 \\
Rafuu Hargisa & 87.2 & 4.16 & 4.16 & 4.38 & 0 \\
Standard Error & \pm 1.28 & \pm 0.93 & \pm 0.6 & \pm 0.93 & \pm 0.97 \\
\hline
\end{tabular}

Morphological and microscopic characteristics of the isolates showed that the genus Fusarium was dominantly isolated from samples collected from the twelve study sites. Morphological characteristics of pure culture isolates were used as a primary screening for fungal identification
(Fig. 6 and 7). As most of the isolates were Fusarium; presence of whitish mycelium and numerous non-branched microconidias were recorded. The microscopic image of the isolates was captured from slide culture preparations (Fig. 8).
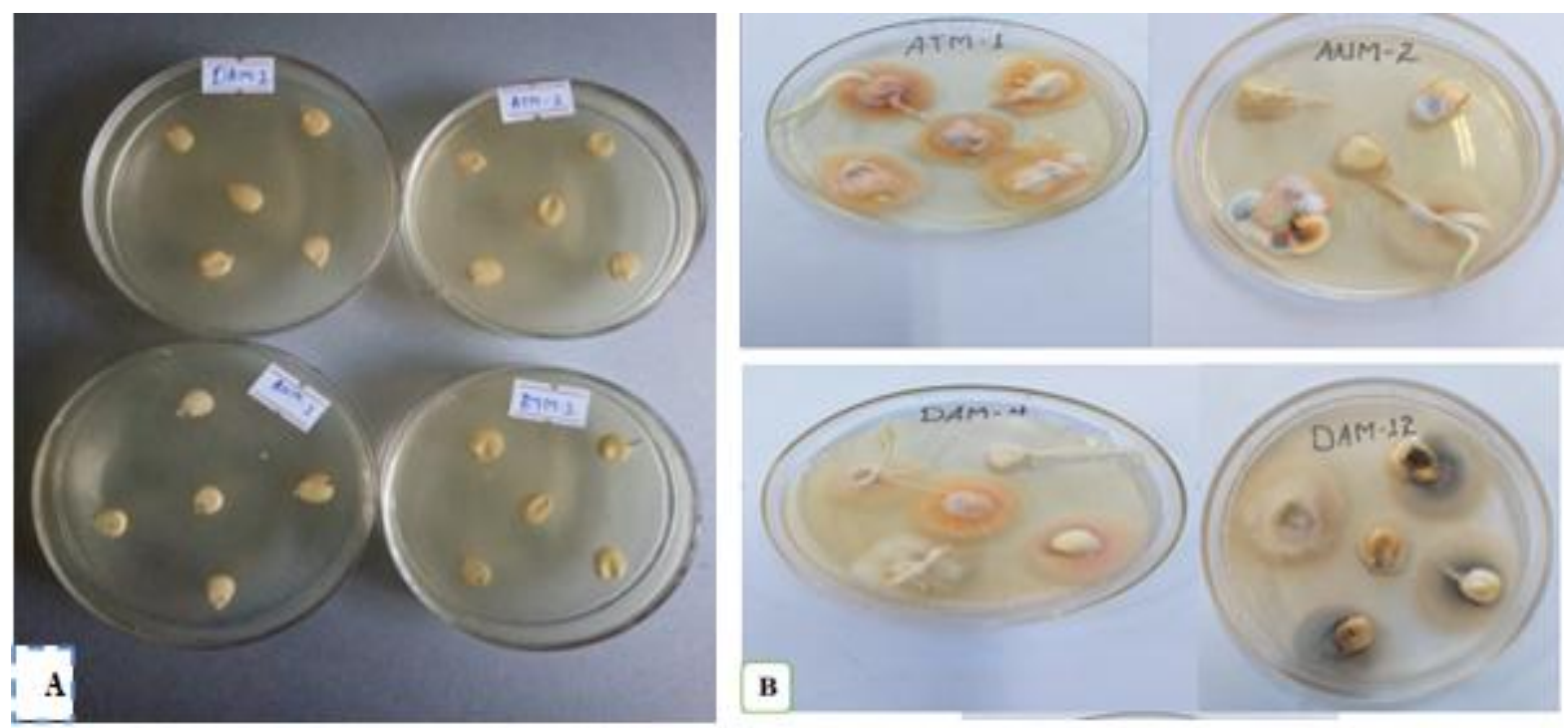

Fig. 6: Isolation of fungi from maize samples. A =inoculated maize sampled before incubation, $\mathrm{B}=$ fungal growth on maize samples after incubation for 3-5 days) (Photo Credit; Temesgen Assefa). 

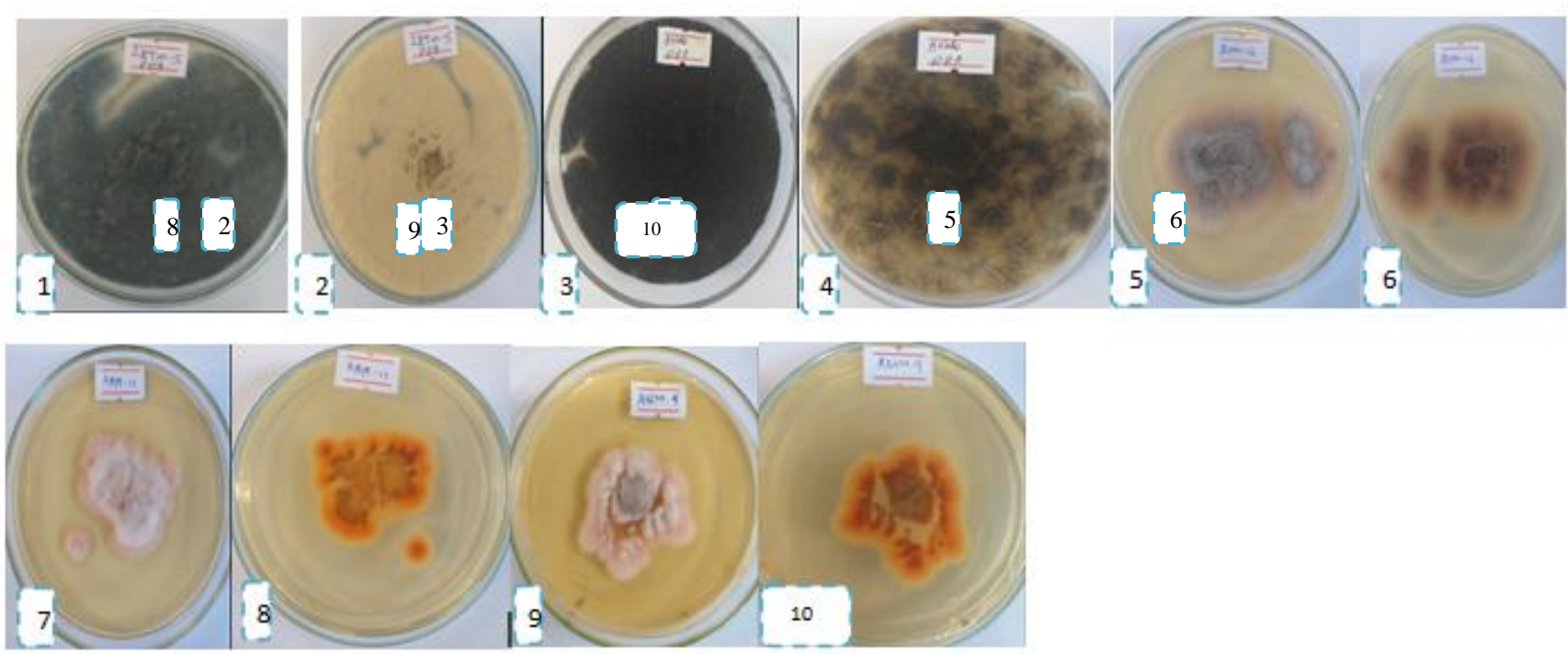

Fig. 7: Five day's old cultural characteristics of fungal pure cultures (1; Aspergillus Obverse side, 2 Aspergillus reverse side; 3, Penicillium Obverse and 4, Penicillium reverse side; 5, 7 and 9 Fusarium Obverse side and 6, 8, and 10 Fusarium reverse side) (Photo Credit; Temesgen Assefa).
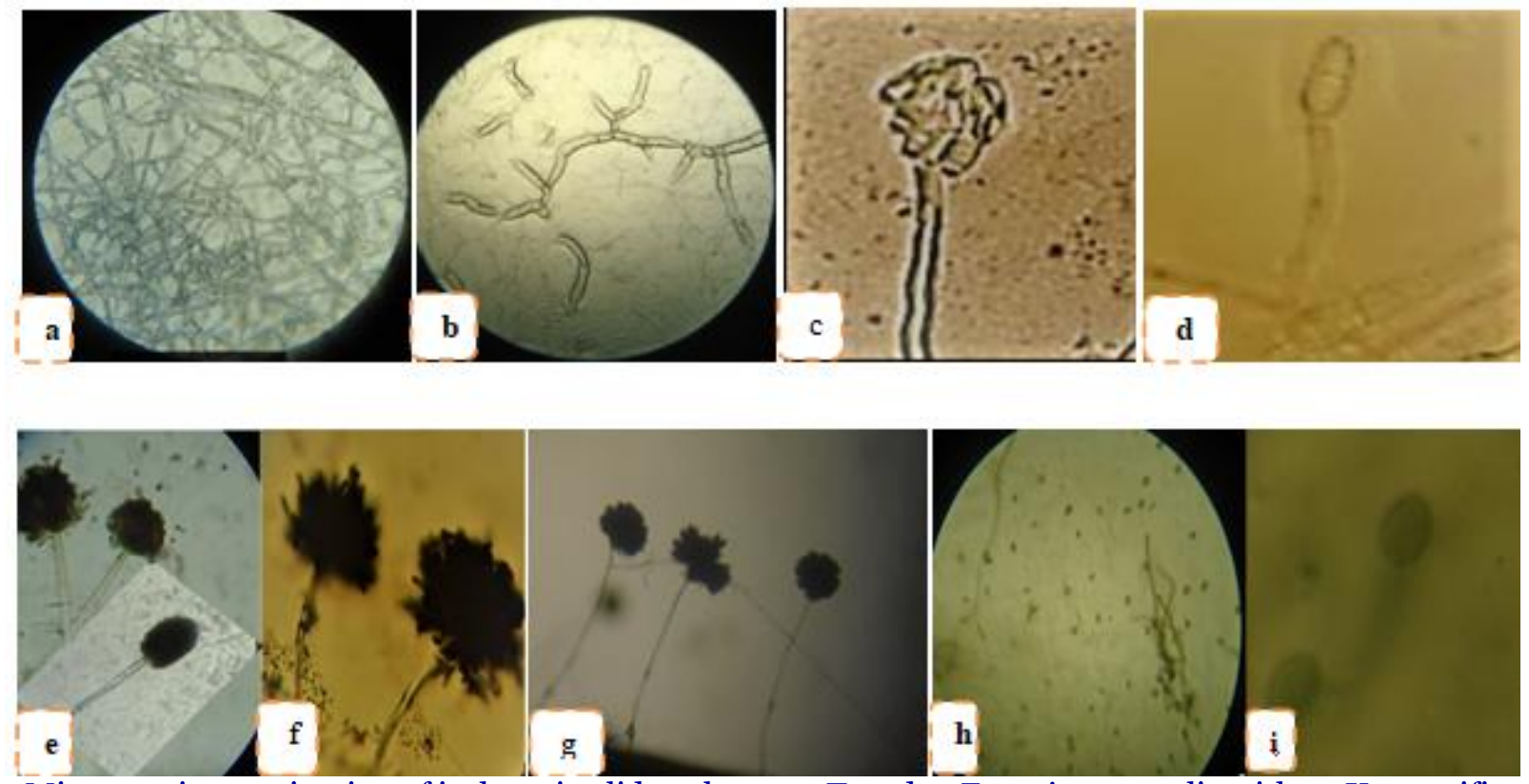

Fig. 8: Microscopic examination of isolates in slide culture, a- Two day Fusarium mycelia with 10 X magnification, b with 40 X magnification; $c$ and d, Two day Fusarium macro conidia with 40 X magnification; e, Aspergillus spore; $\mathrm{f}$, Mucor spore; g, Rhizopus spore; h and i, Fusarium Micro conidia). Note: Slide culture was performed on five day's old pure cultures and further slide cultured for two days (Photo Credit: Temesgen Assefa).

\section{Conclusion and recommendations}

\section{Conclusion}

There was wider mycoflora contamination of maize in the study area. The rate of fungal contamination was higher. Most of the study kebeles have higher incidence of fungal contamination and Dano district showed higher percent of maize contamination among others. 
The mean moisture content obtained in this study was above the National Agricultural Commodities Marketing Association Standards (Queensland, Australia) and this indicated inappropriate drying of the grains was before harvest which has special relevance to maximize mold growth and mycotoxin production.

The genus Fusarium was predominantly recorded in the study sites followed by Penicillium, Mucor/ Rhizopus and Aspergillus. Even if statistically found to be insignificant various factors were tested for correlation with fungal spoilage and each of which showed to have an effect for fungal spoilage in maize. Generally, since molds in maize grains are reported in different parts of the country and worldwide, maize is one of the most reservoirs of fungi.

\section{Recommendations}

From the study it was recommended that awareness creation of farmers, experts and agricultural extension workers about postharvest handling and the importance of diseases and their management is required. Use of holistic, cumulative integrated management, monitoring, and precautionary measures of the stored grain throughout the storage period and Maize breed type and mycoflora association studies have to be concerned which enables to identify resistant and or tolerant maize varieties and screening of effective bio-agents. There is also need to standardize the farmers, grains marketers and consumers to improve their storage facilities. Moreover, further study is required on the molecular identification of the isolates and of the mycotoxin analysis.

\section{Acknowledgement}

This study was financed by Adama Science and Technology University (ASTU) and the entire laboratory activity was done in applied biology department, Microbiology lab. The authors also thank the agricultural experts and extension workers of the study areas.

\section{Conflict of interest statement}

Authors declare that they have no conflict of interest.

\section{References}

Amare, A., 2010. Mycotoxins and surface and internal fungi of maize from Ethiopia. African J. Food Agric. Nutr. Devel. 10 (9), 4109-4123.

Association of Official Analytical Chemists (AOAC), 1995. Official Methods of Analysis of Association of Official Analytical Chemists: Association of Official Analytical Chemists, $16^{\text {th }}$ edition, Vol. I, INC, Virginia, USA.

Barnett, H.L., Hunter, B., 1998. Illustrated genera of imperfect fungi: A new introductory material, $4^{\text {th }}$ Edn., 234p.

Castlellarie, C., Marcos, F., Mutti, J., Cardoso, L., Bartosik, R., 2010. Toxigenic fungi in corn (maize) stored in hermetic plastic bags: National institute of agricultural Technologies, Mardel Plata University Argentina, pp.115-297.

Chemeda, A., Lemlem G., Esayas M., Fikre L., Oliver, H., 2018. Actors' post-harvest maize handling practices and allied mycoflora epidemiology in southwestern Ethiopia: Potential for mycotoxin-producing fungi management. J. Appl. Bot. Food Qual. 91, 237248.

CSA, 2013. Agricultural Sample Survey 2012-2013. Volume I, Area and Production of Crops, Central Statistical Agency, Ethiopia.

Dejene, M., Yuen, J., Sigvald, R., 2004. The impact of storage methods on storage environment and sorghum grain quality. Seed Sci. Technol. $32,511-529$.

Dubale, B., 2014. Factors Affecting quality of grain stored in Ethiopian traditional storage structures and opportunities for improvement. Int. J. Sci. Basic Appl. Res. 18 (1), 235-257.

Dubale, B., 2018. Postharvest losses in Ethiopia and opportunities for reduction. International Int. J. Sci. Basic Appl. Res. 38 (1), 249-262.

El Kinany, S., Achbani, E., Faggroud, M., Ouahmane, L., El Hilali, R., Haggoud, A., Bouamri, R., 2018. Effect of organic fertilizer and commercial arbuscular mycorrhizal fungi on the growth of micropropagated date palm cv. Feggouss. J. Saudi Soc. Agric. Sci. https:// doi.org/10.1016/j.jssas.2018.01.004.

Ezekiel, C.N., Udom, I.E., Frisvad, J.C., Adetunji, M.C., Houbraken, J., Fapohunda, S.O., 2014. Assessment of aflatoxigenic Aspergillus and other fungi in millet and sesame from Plateau State, Nigeria. Mycology. 5, 16-22.

Gtorni, P., Battilani, P., Magan, N., 2009. Effect of 
solute and matric potential on in-vitro growth and sporulation of strains from a new population of Aspergillus flavus in Italy. Fungi Ecol. 1, 101-106.

Hadush, T., May, B. B., Leif, S., Dereje, A., Arne, T., Anne, M. T., 2017. Natural occurrence of Fusarium species and fumonisin on maize grains in Ethiopia. Eur. J. Plant Pathol. 147 (1), 141-155.

Jan, N., Hana, L., Martin, K.M., 2012. Influence of growing $\mathrm{Bt}$ maize on Fusarium infection and mycotoxins content. Plant Protect. Sci. 48, 18-24.

Jelka, P., Visnja, V., Danijela, P., Jadranka, F., Nada, V., Suzana, J., Ksenija, M., 2017. Annual variations of Fusarium mycotoxins in unprocessed maize, wheat and barley from Bosnia and Herzegovin. Croat. J. Food Sci. Technol. 9 (1), 11-18.

Jolly, P.E., Shuaib, F.M., Jiang, Y., Preko, P., Baidoo, J., Stiles, J.K., Wang, J.S., Phillips, T.D., Williams, J.H., 2011. Association of high viral load and abnormal liver function with high aflatoxin B- 1-albumin adducts levels in HIV-positive Ghanaians: preliminary observations. Food Addit. Contam. 28, 12241234.

Kana, J.R., Gnonlonfin, B.G.J., Harvey, J., Wainaina, J., Wanjuki, I., Skilton, R.A., Teguia, A., 2013. Assessment of aflatoxin contamination of maize, peanut meal and poultry feed mixture from different agroecological zones in Cameroon. Toxins. 5, 884-894.

Laura, S., 2019. Storage grain fungi: Agricultural electronic bulletin board, University of Missouri Extension-CAFNER.

Maria, D,L., Michael, S., Otniel, F.S., Sonia, S.C., Catherine, B., Miguel, M. J., Beatriz, L. S., Eugenia, A.V., Rudolf, K., Rainer, S., 2013. Cooccurrence of Mycotoxins in Maize and Poultry Feeds from Brazil by Liquid Chromatography / Tandem Mass Spectrometry. Scient. World J. 1, (1-9).

Negasa, F., Solomon, A., Girma, D., 2019. Effect of traditional and hermetic bag storage structures on fungus contamination of stored maize Grain (Zea mays L.) in Bako, Western Shoa, Ethiopia. Afr. J. Food Sci. 13(3), 57-64.

Patrick, C., Antonio, H., Hon-Kit, Susanna, K., Kwok-Yung, 2010. Agar block smear preparation: A novel method of slide preparation for preservation of native fungal structures for microscopic examination and long-term storage. J. Clin. Microbiol. 48(9), 3053-3061.

Pleadin, J., Vahcic, N., Persi, N., Sevelj, D., Markov, K., and Frece, J. (2013).Fusarium mycotoxins' occurrence in cereals harvested from Croatian fields. Food Cont. 32, 49-54.

Rashid, S., Tefera, N., Ayele, G., 2013. Fertilizer in Ethiopia, An assessment of policies, value chain and profitability. Discussion Paper 01304. Washington, DC: IFPRI.

Samuel, A., Bankole, M.S., Winfried, D., 2011. Survey of ergosterol, zearalenone and trichothecene contamination in maize from Nigeria. J. Food Comp. Anal. 23, 837-842.

Sarah, K., Catriona, H., Helen, A., David, E., 2016. Descriptions of Medical Fungi: fungi-Indexes. Mycology-Indexes, Third Edition, New style Printing 41 Manchester Street Mile End, South Australia, 5031, pp.1-278.

Suleiman, M.N., Omafe, O.M., 2013. Activity of three medicinal plants on fungi isolated from stored maize seeds (Zea mays (L.). Global J. Med. Plant Res. 1(1), 77-81.

Temesgen, A., Teshome, G., 2018. Major mycotoxins occurrence, prevention and control approaches. Biotechnol. Mol. Biol. Rev. 12 (1), 1-11.

Tesfaye, W., Dawit, A., 1998. Toxigenic Fusarium species in maize grain in Ethiopia. In: Maize Production Technology for the future: Challenges and Opportunities. Proceedings of the $6^{\text {th }}$ Eastern and Southern Africa Regional Maize Conference. CIMMYT/EARO, 132-134.

Tesfaye, W., Dawit, A., 2000. Common toxigenic Fusarium species in maize grain in Ethiopia. SINET Eth. J. Sci. 23, 73-86.

Tomoko, I., Naoko, T.A., Noriyuki, O., Shuichi, O., Tsutomu, S., Toshiaki, K., Isamu, Y., Makoto, K., 2007. Reduced contamination by the Fusarium mycotoxin zearalenone in maize kernels through genetic modification with a detoxification gene. Appl. Environ. Microbiol. 73 (5), 1622-1629.

Tsedeke, A., Bekele, S., Abebe, M., Dagne, W., Yilma, K., Kindie, T., Menale, K., Gezahegn, B., Berhanu, T., Tolera, K., 2015. Factors that transformed maize productivity in Ethiopia. Food Sci. 7, 965-981.

Wei, Y., Siyu, G., Ying, X., Ayodeji, B.,Wenpeng, S., Xiuhong, X., 2018. Compost addition enhanced 
hyphal growth and sporulation of arbuscular mycorrhizal fungi without affecting their community composition in the soil. Front Microbiol. 9, 169.

Yesuf, E., Misganaw, M., Wondwesen, S., 2015. Assessment of important plant disease of major crops (sorghum, maize, common bean, coffee, mung bean, cowpea) in south Omo and Segen peoples zone of Ethiopia. Curr. Agric. Res. J. 3 (1), 75-79.

Yibrah, B., Dereje, A., 2015. Postharvest loss assessment survey-in Ethiopia, baseline information on maize (Zea mays L.) Postharvest Loss Assessment, 1-40.

\section{How to cite this article:}

Temesgen, A. G., Teshome, G. B., 2019. Isolation and enumeration of fungi and determination of contributing factors to fungal spoilage in maize (Zea mays L.) originated from east and west Shewa Zones of Oromia, Ethiopia. Int. J. Curr. Res. Biosci. Plant Biol. 6(12), 8-19.

doi: https://doi.org/10.20546/ijcrbp.2019.612.002 